\title{
RESEARCH
}

Open Access

\section{The C18:3n6/C22:4n6 ratio is a good lipid marker of chronic kidney disease (CKD) progression}

\author{
Małgorzata Szczuko ${ }^{1 *}$, Małgorzata Kaczkan², Sylwia Małgorzewicz², Przemysław Rutkowski ${ }^{3}$, \\ Alicja Dębska-Ślizień ${ }^{4}$ and Ewa Stachowska ${ }^{1}$
}

\begin{abstract}
Background: Chronic kidney disease (CKD) is a major challenge for public health due to increased risk of cardiovascular diseases (CVD) and premature death. The aim of this study was to determine the clinical picture of FA and the course of the pathophysiological mechanisms of CKD.

Methods: The study involved 149 patients with CKD and a control group including 43 people. Fatty acid profiles were investigated using gas chromatography. A total of 30 fatty acids and their derivatives were identified and quantified. The omega3, omega6, SFA, MUFA, and PUFA fatty acid contents were calculated. The correlation matrix was obtained for parameters relating to patients with CKD vs. FA, taking patients' sex into consideration. The index C18:3n6/C22:4n6 was calculated according to the length of the treatment. Statistica 12.0 software (Tulsa, Oklahoma, USA) was used for the statistical analyses.

Results: The results showed decreased levels of total PUFA and increased concentrations of MUFA, including the activation of the palmitic and oleic acid pathway. An increase in the levels of n-6 9C22: 4n6 family fatty acids in all the patients and a reduction in the n-3 family (EPA, DHA) were observed. C18:3n6 was negatively correlated and C22:4n6 was positively correlated with the duration of the treatment. The index C18:3n6/C22:4n6 was defined as a new marker in the progression of the disease. Moreover, the index C18:3n6/ C22:4n6 was drastically decreased in later period. Nervonic acid was higher in the CKD group. In the group of men with CKD, there was a negative correlation between the excretion of $\mathrm{K}+$, anthropometric measurements, and the levels of EPA and DHA.

Conclusions: The course of inflammation in CKD occurs through the decrease in PUFA and the synthesis of MUFA. The dominating cascade of changes is the elongation of GLA-C18:3n6 into DGLA-C20:3n6 and AA-C20:4n6. As CKD progresses, along with worsening anthropometrical parameters and increased secretion of potassium, the activity of

6-desaturase decreases, reducing the synthesis of EPA and DHA. The synthesis of AdA-C22:4n6 increases and the ratio C18:3n6/C22:4n6 drastically decreases after 5 years. This parameter can be used to diagnose disease progression.
\end{abstract}

Keywords: Fatty acid, Chronic kidney disease, Adrenic acid, Docosatetraenoate acid, Gamma linoleic acid

\footnotetext{
* Correspondence: malgorzata.szczuko@pum.edu.pl

'Department of Human Nutrition and Metabolomics, Pomeranian Medical University in Szczecin, Szczecin, Poland

Full list of author information is available at the end of the article
}

(c) The Author(s). 2020 Open Access This article is licensed under a Creative Commons Attribution 4.0 International License, which permits use, sharing, adaptation, distribution and reproduction in any medium or format, as long as you give appropriate credit to the original author(s) and the source, provide a link to the Creative Commons licence, and indicate if changes were made. The images or other third party material in this article are included in the article's Creative Commons licence, unless indicated otherwise in a credit line to the material. If material is not included in the article's Creative Commons licence and your intended use is not permitted by statutory regulation or exceeds the permitted use, you will need to obtain permission directly from the copyright holder. To view a copy of this licence, visit http://creativecommons.org/licenses/by/4.0/ The Creative Commons Public Domain Dedication waiver (http://creativecommons.org/publicdomain/zero/1.0/) applies to the data made available in this article, unless otherwise stated in a credit line to the data. 


\section{Highlights}

We present a clinical picture of free fatty acid (FFA) and the course of the pathophysiological mechanisms of chronic kidney disease (CKD).

The results showed decreased levels of total polyunsaturated fatty acids (PUFA) and increased concentrations of monounsaturated fatty acids (MUFA), including the activation of the palmitic and oleic acid pathway.

The index C18:3n6/C22:4n6 was stable for up to 5 years of treatment but drastically decreased in the later period. This parameter can be used to diagnose disease progression.

The dominating cascade of changes is the elongation of GLA-C18:3n6 into DGLA-C20:3n6 and AA-C20:4n6.

\section{Background}

Chronic kidney disease (CKD) is a major challenge for public health due to its high incidence, common progression to end-stage renal disease (ESRD), and the higher risk of cardiovascular disease (CVD) and premature death $[1,2]$. The profile of fatty acids (FA) changes due to diet, but it also changes in some diseases, such as debilitating diseases that lead to malnutrition and increased catabolism (cachexia) [3].

Fatty acids (FA) are an important source of energy but also act as signal molecules in various cellular processes. Hirasawa et al. found a connection between the secretion of intestinal incretin peptides and an increased level of free insulin [4]. It was shown that the receptor coupled with G protein, GPR120, which is abundantly exprimated in intestines, acts as a receptor for unsaturated long-chained FA. Therefore, the stimulation of GPR120 by FA promotes the secretion of GLP-1 (the strongest insulinotropic incretin) in vitro and in vivo, thus increasing free insulin. So far, the studies on FA have suggested that the level of FA in blood plasma mainly results from the diet. However, our studies show that in patients with CKD the concentration of FA in plasma is dependent on the stage of the disease and the catabolism of adipose tissue, which takes part in the progression of inflammation and is the cause of CKD development. Such a conclusion was also drawn by other researchers: Afshinnia et al. connected an increased level of saturated FA C16:0-C20:0 with impaired $\beta$-oxidation of FA and reverse partitioning/binding into complex lipids as mechanisms facilitating changes in lipid metabolism which characterize progressing CKD [5]. Inflammatory stress enhances kidney damage through the activation of the CD36 pathway. This mechanism may occur in obese people with chronic inflammation, which makes them susceptible to CKD [6]. It seems that increased fat content in liver is linked to increased occurrence of mild and heavy albuminuria and decreased glomerular filtration rate (GFR). Therefore, non-alcoholic fatty liver disease
(NAFLD) may be a risk factor for diabetic nephropathy (DN), and increased fat content in liver may be connected to higher DN risk [7]. However, these results are not consistent among various researchers. Zhan et al., when examining 413 patients with type 2 diabetes (T2DM) and with or without NAFLD, did not observe this connection between NAFLD and DN frequency in patients with T2DM [8]. In contradiction to that, two cohort studies performed by Targher et al. showed that renal disfunction was significantly more frequent in patients with NAFLD $[9,10]$. The authors of the study already compared the FA profile of CKD patients with the profile of patients with Metabolic Syndrome (MetS); it was observed that there had been an increase in the amounts of all FAs in plasma in the CKD group, especially in the case of palmitic acid (C16:0) and the derivatives of stearic acid (C18:0), higher than in the MetS patients; this may result from the decomposition of adipose tissue and the progressing devastation of the organism [11]. Furthermore, stearoyl-CoA desaturase (SCD) is a reticulum enzyme that catalyzes of monounsaturated fatty acids from saturated fatty acids [12]. The preferred substrates are palmitoyl- and stearoyl-CoA, which get converted into palmitoleoyl- and oleoyl-CoA. These products are the most widespread monounsaturated fatty acids (MUFA) in the lipids, including phospholipids, triglycerides, cholesteryl esters, wax esters, and alkyldiacylglycerols [13]. Given the multiple roles of MUFA, variation in SCD activity in mammals would be expected to have an different effects on metabolism and physiology, including differentiation, insulin sensitivity, metabolic rate, adiposity, obesity, atherosclerosis and cancer [12]. It is also likely that both diseases such as atypical hemolytic-uremic syndrome (aHUS) and membranoproliferative glomerulonephritis (MPGN) associated with rather acute renal failure under the influence of infection (E. coli serotype c157: H7, Shigella, Yersinia, Streptococus, lupus erythematosus) depending on the immune mechanism with the participation of the $\mathrm{C} 3$ complement component may also be one of the mechanisms of FA synthesis change [14-16]. Because in our research we had a group of subjects older in the majority and there were no cases of acute renal failure, this mechanism is probably considered to be less significant but possible. Moreover, in MetS, auxiliary metabolic pathways are activated for oleic acid and cause the simultaneous inhibition of EPA and DHA synthesis from ALA, whereas in the CKD group, we observe increased synthesis of EPA and DHA. The higher increase of nervonic acid (C24:1) in CKD suggests a higher degree of demyelination and loss of anons [11].

The aim of the present study was to investigate the influence of the duration of the disease on the clinical picture of FA, which can help in understanding the mechanisms of CKD pathophysiology and in adjusting therapy to be better for patients. 


\section{Methods}

\section{Participants in the study}

All laboratory measurements characterizing the patients with CKD were performed at Central Laboratory Medical University of Gdańsk under rigorous quality control. The studies concerning FA contents were carried out at the Department of Human $\mathrm{Nu}$ trition and Metabolomics, Pomeranian Medical University in Szczecin.

This study was an ongoing multicentre prospective cohort study. It involved 192 Caucasian people from the central European region. The first test group comprised patients with chronic kidney disease (CKD). These were 62 women at the age of $65.9 \pm 13.98$, with an average body weight of $69.33 \pm 18.47 \mathrm{~kg}$, and 87 men at the age of $63.4 \pm 15.9$, with an average weight of $76.6 \pm 15.97 \mathrm{~kg}$. Other parameters characteristic of the disease profile are presented in Table 1.

Criteria for starting renal replacement therapy:

1. Clinical

- if the pacjent has symptoms of uremia, conduction, uncontrolled hypertension or signs of malnutrition, hyperkalemia, severe metabolic acidosis,

2. Biochemical

- $\mathrm{eGFR}<10 \mathrm{ml} / \mathrm{min}$ or $<15$ in people with diabetes, urea in serum $160-200 \mathrm{mg} / \mathrm{dl}$
The decision is always made individually.

The second group, i.e., the control group, comprised 43 healthy people, including 19 women at the age of $53.21 \pm 4.16$ and with an average weight of $59.39 \pm 4.72$ $\mathrm{kg}$ and 24 men at the age of $57.10 \pm 4.38$ and with an average weight of $76.42 \pm 5.27 \mathrm{~kg}$. In the control group, all women and men had appropriate body weight with respect to height (Table 2).

\section{FAME extraction}

Blood plasma was obtained from whole-blood samples collected in tubes containing EDTA as an anticoagulant by centrifugation for $10 \mathrm{~min}$ at $1200 \mathrm{G}$. Plasma samples were stored at $-80{ }^{\circ} \mathrm{C}$. Fatty acids were extracted according to the Folch method and analyzed by gas chromatography. A quantity of $0.5 \mathrm{ml}$ of plasma was saponified with $1 \mathrm{ml}$ of $2 \mathrm{~mol} / \mathrm{L} \mathrm{KOH}$ methanolic solution at $70{ }^{\circ} \mathrm{C}$ for $20 \mathrm{~min}$ and then methylated with $2 \mathrm{ml}$ of $14 \%$ boron trifluoride in methanol under the same conditions. Then $2 \mathrm{ml}$ of $\mathrm{n}$-hexane and $10 \mathrm{ml}$ of saturated $\mathrm{NaCl}$ solution were added. A quantity of $1 \mathrm{ml}$ of the $\mathrm{n}$-hexane phase was collected for analysis.

\section{Gas chromatography (GC) anaylsis}

The analysis of the fatty acids profile in the plasma was performed using gas chromatography on an Agilent Technologies 7890A GC System, and the compounds were separated using a Capillary GC Column $(15 \mathrm{~mm} \times$ $0.10 \mathrm{~mm}, 0.10 \mu \mathrm{m}$; Supelco, Bellefonte, PA, United States) (SUPELCOWAX ${ }^{\mathrm{TM}}$ 10). The chromatographic

Table 1 Characteristics of the patients with chronic kidney disease (CKD) divided into sexes

\begin{tabular}{|c|c|c|c|}
\hline Characteristic & $\begin{array}{l}\text { Women } n=62 \\
\text { Avg +SD }\end{array}$ & $\begin{array}{l}\text { Men } n=87 \\
\text { Avg + SD }\end{array}$ & Significance of differences \\
\hline Age ([years)] & $65.88 \pm 13.98$ & $63.40 \pm 15.90$ & NS \\
\hline Weight $([k g)]$ & $69.33 \pm 18.47$ & $76.60 \pm 15.97$ & 0.0479 \\
\hline BMI [kg/m2] & $24.81 \pm 6.14$ & $25.28 \pm 6.6$ & NS \\
\hline Ca $[\mathrm{mg} / \mathrm{dl}]$ & $8.66 \pm 0.97$ & $8.47 \pm 0.79$ & NS \\
\hline I PHOS [mg/dl] & $5.375 \pm 1.36$ & $5.03 \pm 1.26$ & NS \\
\hline iPTH [pg/ml] & $705.8 \pm 663.9$ & $416.2 \pm 364.7$ & 0.0097 \\
\hline CREA [mg/dl] & $7.49 \pm 2.07$ & $8.41 \pm 2.35$ & NS \\
\hline $\mathrm{HGB}[\mathrm{g} / \mathrm{dl}]$ & $10.67 \pm 1.11$ & $10.74 \pm 1.37$ & NS \\
\hline \%TSAT [\%] & $30.57 \pm 15.22$ & $29.24 \pm 13.29$ & NS \\
\hline FER [ug/l] & $954,9 \pm 739.5$ & $689.2 \pm 616.9$ & 0.0000 \\
\hline ALB $[\mathrm{g} / \mathrm{l}]$ & $34.56 \pm 4.31$ & $35.80 \pm 3.92$ & NS \\
\hline $\mathrm{K}[\mathrm{mEq} / \mathrm{L}]$ & $5.347 \pm 0.64$ & $5.261 \pm 0.63$ & NS \\
\hline Treatment duration [months] & $62.42 \pm 79.38$ & $46.29 \pm 52.01$ & NS \\
\hline Body surface [m2] & $1.727 \pm 0.21$ & $1.846 \pm 0.186$ & 0.0074 \\
\hline $\mathrm{Kt} / \mathrm{V}$ & $1.716 \pm 0.31$ & $1.579 \pm 0.33$ & 0.0136 \\
\hline $\mathrm{nPCR}[\mathrm{g} / \mathrm{kg} / \mathrm{day}]$ & $1.071 \pm 0.24$ & $1.09 \pm 0.267$ & NS \\
\hline Ca $\times$ P [mg2/dl2] & $47.18 \pm 11.63$ & $42.096 \pm 12.457$ & NS \\
\hline
\end{tabular}


Table 2 Characteristics of the control groups divided into sexes

\begin{tabular}{llll}
\hline Characteristic & $\begin{array}{l}\text { Women } n=15 \\
\text { Avg }+ \text { SD }\end{array}$ & $\begin{array}{l}\text { Men } n=39 \\
\text { Avg }+ \text { SD }\end{array}$ & Significance of differences \\
\hline Age ([years)] & $53.21 \pm 4.16$ & $57.10 \pm 4.38$ & NS \\
Weight ([kg)] & $59.39 \pm 4.72$ & $76.42 \pm 5.27$ & 0.0031 \\
BMl [kg/m2] & $22.86 \pm 1.21$ & $24.31 \pm 1.26$ & NS \\
\hline
\end{tabular}

conditions were as follows: the initial temperature was $40^{\circ} \mathrm{C}$ for $0.5 \mathrm{~min}$; it was increased at a rate of $25^{\circ} \mathrm{C} / \mathrm{min}$ to $195^{\circ} \mathrm{C}(0 \mathrm{~min})$; next, it was increased at a rate of $3{ }^{\circ} \mathrm{C} /$ min to $205^{\circ} \mathrm{C}(0 \mathrm{~min})$ and then increased at a rate of $8{ }^{\circ} \mathrm{C} / \mathrm{min}$ to $250^{\circ} \mathrm{C}$ for $0.5 \mathrm{~min}$. The total analysis lasted approximately $16.158 \mathrm{~min}$ and the gas flow rate was 1 $\mathrm{mL} / \mathrm{min}$ with hydrogen as the carrier gas. Fatty acids were identified by comparing their retention times with those of commercially available standards. The analysis of the fatty acids content in particular samples was performed using specialist ChemStation Software (Agilent Technologies, UK). Qualitative identification of the fatty acids was performed by comparing retention times to those of the standards, and the quantity of a specific fatty acid was given as a percentage of the fatty acids in the total amount of analysed compounds (excluding the standard-heneicosanoic acid (C21:0)).

The fatty acid content was calculated as follows [17]:

sum of the omega3 fatty acids: $(\mathrm{n} 3)=\mathrm{C} 18: 3 \mathrm{n} 3+\mathrm{C} 20$ :

$5 \mathrm{n} 3+\mathrm{C} 22: 5 \mathrm{n} 3+\mathrm{C} 22: 6 \mathrm{n} 3$

sum of the omega 6 fatty acids: $(\mathrm{n} 6)=\mathrm{C} 18: 2 \mathrm{n} 6+\mathrm{C} 18$ :

$3 n 6+C 20: 3 n 6+C 20: 4 n 6+C 22: 4 n 6$

sum of the saturated fatty acids:

$($ SFAs $)=\mathrm{C} 8: 0+\mathrm{C} 10: 0+\mathrm{C} 11: 0+\mathrm{C} 12: 0+\mathrm{C} 14: 0+\mathrm{C} 15: 0+$ $\mathrm{C} 16: 0+\mathrm{C} 17: 0+\mathrm{C} 18: 0+\mathrm{C} 20: 0+\mathrm{C} 22: 0+\mathrm{C} 23: 0+\mathrm{C} 24: 0) ;$

sum of the monounsaturated fatty acids:

$($ MUFAs $)=$ C14:1n-9 + 16:1n7 + C17:1 + C18:1 + C22:

$1+\mathrm{C} 24: 1)$,

sum of the poly-unsaturated fatty acids:

$($ PUFAs $)=18: 2 \mathrm{n} 6+\mathrm{C} 18: 3 \mathrm{n} 6+\mathrm{C} 18: 3 \mathrm{n} 3+\mathrm{C} 18: 3 \mathrm{n} 6+$

$\mathrm{C} 20: 3 \mathrm{n} 3+\mathrm{C} 20: 4 \mathrm{n} 6+\mathrm{C} 20: 5 \mathrm{n} 3+\mathrm{C} 22: 4 \mathrm{n} 6+\mathrm{C} 22: 5 \mathrm{n} 3+$

C22:6n3. The UFAs were the sum of the MUFAs and PUFAs.

\section{Statistical analysis}

Statistica 12.0 software (Tulsa, Oklahoma, USA) was used for the statistical analyses, and all results were expressed as mean \pm standard deviation. As the distribution in most cases was normal (Shapiro-Wilk Test), parametric $t$-testing was used for comparisons between groups (Men CKD vs. CG; Women CKD vs. CG; Women CKD vs. Men CKD), and $p \leq 0.05$ was considered statistically significant. The correlation matrix was obtained for the biochemical and anthropometric parameters of patients with CKD vs. FA taking patients' sex into consideration. In Tables 6 and 7 are presented the correlations of those FA for which there were at least two significant correlations. Next, all the patients with CKD were divided into six groups (of similar size) according to the length of the treatment, and the index $\mathrm{C} 18: 3 \mathrm{n} 6 / \mathrm{C} 22: 4 \mathrm{n} 6$ was calculated to compare the significance of differences between the groups. Due to the multitiude of statistically insignificant resolts, we perfomed a post hoc power analysis. The power of tests which showed no statistical significanse, was below the recomended level of 0,8 . On the over hand tests showing statistical significans had an acceptable power reaching as high as 0,82 .

\section{Results}

\section{Participants in the study}

The group of patients with CKD varied depending on the sex. The group of women with CKD differed significantly when compared to men with CKD with respect to body weight, intact parathyroid hormone (iPTH), concentrations of creatinine and ferritin, duration of the treatment, body surface, $\mathrm{Kt} / \mathrm{V}$ (dialysis adequacy, Table 1 ). In the control groups, the differences between the sexes related only to body weight (Table 2).

\section{Comparison of $\mathrm{FA}$ percentages in plasma}

Analyses of the percentages of FA in plasma in the group of men with CKD showed that there are fundamental differences in the concentration of the majority of fatty acids in comparison to the control group (Table 3). The most significant differences in mediumchain FA related to the decreases in C8:0, C11:0, C17:0, $\mathrm{C} 18: 0$, and C18:2n6 and the increases in C10:0, C15:0, C16:0, C16:1, C18:1n9, and C18:1 t. Also, decreased levels of C20:3n6 C20:5n3, C22:5n3, and C22:6n 3 and increased levels of C22:0, C23:0, C22:4n6, and C24:1 were observed. These changes were basically connected with the increased SFA and omega- 6 family (C22:4n6) concentrations and the reduction in the index C18:3n6/ C22:4n6 in comparison to the control group (Table 3).

A comparison of the group of women with CKD with the control group showed lower concentrations of SFA, especially C8:0, C11:0, C17:0, C18:0, and C20:0, and lower levels of C17:1, C18 2n6, C20:3n6, C20:4n6, C20: 5n3, C22:5n3, and C22:6n3. However, increased percentages were noted in the cases of C10:0, C14:1, C16:1, C18:1n9, C18:1 t, C22:4n6, and C24:0 (Table 4). To summarize, in the group of women with CKD, there was a reduction in the ratio of the $n-3$ family (EPA, DHA) and a several-fold increase in the $n-6$ family (C22:4n6) but reductions in C20:3n6 and C20:4n6. Similarly, as in the group of men with CKD, total SFA was unchanged relative to the control group. There was an increase in the total MUFA and drop in the PUFA and a reduced C18:3n6/C22:4n6 ratio in comparison with the control 
Table 3 Comparison of the percentages of FFA in the plasma of men with CKD vs. the control group

\begin{tabular}{|c|c|c|c|c|c|}
\hline \multirow[t]{2}{*}{ PARAMETER } & \multicolumn{2}{|c|}{ MEN (CKD) } & \multicolumn{2}{|c|}{ CONTROL } & \multirow[t]{2}{*}{ p.value } \\
\hline & MEAN & SD & MEAN & SD & \\
\hline C 8:0 Caprylic acid & 0.0073 & 0.033 & 0.0611 & 0.024 & $p<0.05$ \\
\hline C10:0 Capric acid & 0.9849 & 0.624 & 0.0098 & 0.020 & $p<0.05$ \\
\hline C11:0 Undecanoic acid & 0.0236 & 0.015 & 0.0636 & 0.021 & $p<0.05$ \\
\hline C12:0 Lauric acid & 0.1460 & 0.117 & 0.1556 & 0.069 & NS \\
\hline C14:0 Myristic acid & 1.3045 & 0.793 & 1.2106 & 0.337 & NS \\
\hline C14:1 Myristolenic acid & 0.0788 & 0.072 & 0.0783 & 0.077 & NS \\
\hline C15:0 Pentadecanoid acid & 0.3474 & 0.142 & 0.2779 & 0.064 & $p<0.05$ \\
\hline C16:0 Palmitic acid & 28.616 & 1.975 & 26.598 & 2.097 & $p<0.05$ \\
\hline C16:1 Palmitoleic acid & 1.8664 & 0.812 & 1.4488 & 0.524 & $p<0.05$ \\
\hline C17:0 Heptadecanoid acid & 0.3413 & 0.082 & 0.4520 & 0.050 & $p<0.05$ \\
\hline C17:1 cis-10- Heptadecanoid acid & 0.1155 & 0.088 & 0.1347 & 0.059 & NS \\
\hline C18:0 Stearic acid & 11.469 & 1.451 & 13.145 & 2.073 & $p<0.05$ \\
\hline C18:1n9 ct Oleic acid & 22.933 & 3.232 & 19.585 & 2.435 & $p<0.05$ \\
\hline C18:1 tans vaccinic acid & 2.1048 & 0.304 & 1.7612 & 0.228 & $p<0.05$ \\
\hline C18:2n6c Linoleic acid & 16.856 & 3.385 & 20.509 & 2.009 & $p<0.05$ \\
\hline C18:3n6 gamma linoleic acid & 0.1980 & 0.090 & 0.2206 & 0.093 & NS \\
\hline C18:3n3 linolenic acid & 0.6846 & 0.307 & 0.5976 & 0.230 & NS \\
\hline C20:0 Arachidic acid & 0.1623 & 0.051 & 0.1548 & 0.083 & NS \\
\hline C22:1/C20:1 cis11- eicosanic acid & 0.2369 & 0.079 & 0.2209 & 0.088 & NS \\
\hline C20:2 cis-11-eicodienoic acid & 0.2041 & 0.063 & 0.1820 & 0.018 & NS \\
\hline C20:3n6 eicosatrienoic acid & 1.0763 & 0.260 & 1.3352 & 0.340 & $p<0.05$ \\
\hline C20:4n6 Arachidonic acid & 5.7957 & 1.278 & 6.4857 & 1.429 & NS \\
\hline C20:5n3 EPA & 0.7535 & 0.466 & 1.4693 & 1.193 & $p<0.05$ \\
\hline C22:0 Behenic acid & 0.0531 & 0.046 & 0.0148 & 0.032 & $p<0.05$ \\
\hline C23:0 tricosanoic acid & 0.2310 & 0.400 & 0.0555 & 0.065 & $p<0.05$ \\
\hline C22:4n6 (docosatetraenoate) & 0.3210 & 0.199 & 0.1295 & 0.032 & $p<0.05$ \\
\hline C22:5w3 (docosapentaenate) & 0.5764 & 0.172 & 0.6740 & 0.083 & $p<0.05$ \\
\hline C24:0 Lignoceric acid & .0 .3034 & 0.852 & 0.5165 & 0.882 & NS \\
\hline C22:6n3 DHA & 1.912 & 0.664 & 2.1039 & 1.576 & $p<0.05$ \\
\hline C24:1 Nervonic acid & 0.0566 & 0.075 & 0 & 0 & $p<0.05$ \\
\hline n3 & 3.8038 & 1.227 & 4.8446 & 1.890 & $p<0.05$ \\
\hline n6 & 23.496 & 4.886 & 28.680 & 3.825 & $p<0.05$ \\
\hline SFA & 42.979 & 7.470 & 42.712 & 3.987 & NS \\
\hline MUFA & 27.034 & 5.523 & 23.228 & 2.786 & $p<0.05$ \\
\hline PUFA & 27.692 & 5.524 & 33.706 & 3.759 & NS \\
\hline C18:3n6/C22:4n6 & 0.9261 & 0.931 & 1.7037 & 0.999 & $p<0.05$ \\
\hline
\end{tabular}

group (Table 4). When comparing men with CKD to women with CKD, there were a few differences in the percentage of FA in plasma which related to higher concentrations of $\mathrm{C} 18: 0, \mathrm{C} 18: 1 \mathrm{t}$, and $\mathrm{C} 20: 0$ in the male group with $\mathrm{CKD}$ and of $\mathrm{C} 18: 3 \mathrm{n} 6$ in the female group with CKD (Table 5).

\section{Correlation matrix}

Based on the correlation matrix for parameters of women with CKD and FA concentration in blood plasma, a negative correlation for both sexes was observed between C10:0 and albumin (ALB), and a positive correlation was noted for women with the level of 
Table 4 Comparison of the percentages of FFA in the plasma of women with CKD vs. the control group

\begin{tabular}{|c|c|c|c|c|c|}
\hline \multirow[t]{2}{*}{ PARAMETER } & \multicolumn{2}{|c|}{ WOMEN (CKD) } & \multicolumn{2}{|c|}{ CONTROL } & \multirow[t]{2}{*}{ p.value } \\
\hline & MEAN & SD & MEAN & SD & \\
\hline C 8:0 Caprylic acid & 0.0070 & 0.022 & 0.0568 & 0.026 & $p<0.05$ \\
\hline C10:0 Capric acid & 0.8944 & 0.638 & 0.0172 & 0.022 & $p<0.05$ \\
\hline C11:0 Undecanoic acid & 0.0209 & 0.013 & 0.0840 & 0.022 & $p<0.05$ \\
\hline C12:0 Lauric acid & 0.1570 & 0.118 & 0.1473 & 0.049 & NS \\
\hline C14:0 Myristic acid & 1.3306 & 0.605 & 1.0995 & 0.348 & NS \\
\hline C14:1 Myristolenic acid & 0.0877 & 0.063 & 0.0587 & 0.044 & $p<0.05$ \\
\hline C15:0 Pentadecanoid acid & 0.3476 & 0.133 & 0.2812 & 0.064 & NS \\
\hline C16:0 Palmitic acid & 27.8722 & 2.781 & 27.6025 & 1.579 & NS \\
\hline C16:1 Palmitoleic acid & 1.9987 & 0.678 & 1.5677 & 0.371 & $p<0.05$ \\
\hline C17:0 Heptadecanoid acid & 0.3519 & 0.088 & 0.4528 & 0.049 & $p<0.05$ \\
\hline C17:1 cis-10- Heptadecanoid acid & 0.1141 & 0.102 & 0.1387 & 0.065 & $p<0.05$ \\
\hline C18:0 Stearic acid & 10.9025 & 1.855 & 12.3402 & 1.241 & $p<0.05$ \\
\hline C18:1n9 ct Oleic acid & 22.8029 & 4.134 & 18.8294 & 1.103 & $p<0.05$ \\
\hline C18:1 tans vaccinic acid & 1.9982 & 0.331 & 1.7374 & 0.158 & $p<0.05$ \\
\hline C18:2n6c Linoleic acid & 17.8465 & 2.910 & 20.5960 & 1.719 & $p<0.05$ \\
\hline C18:3n6 gamma linoleic acid & 0.2418 & 0.123 & 0.2429 & 0.065 & NS \\
\hline C18:3n3 linolenic acid & 0.6727 & 0.307 & 0.6145 & 0.166 & NS \\
\hline C20:0 Arachidic acid & 0.1449 & 0.051 & 0.1677 & 0.030 & $p<0.05$ \\
\hline C22:1/C20:1 cis11- eicosanic acid & 0.2247 & 0.116 & 0.2180 & 0.034 & NS \\
\hline C20:2 cis-11-eicodienoic acid & 0.1893 & 0.059 & 0.2170 & 0.032 & $p<0.05$ \\
\hline C20:3n6 eicosatrienoic acid & 1.1222 & 0.294 & 1.5610 & 0.423 & $p<0.05$ \\
\hline C20:4n6 Arachidonic acid & 5.9699 & 1.299 & 7.5353 & 1.155 & $p<0.05$ \\
\hline C20:5n3 EPA & 0.7960 & 0.371 & 0.9682 & 0.248 & $p<0.05$ \\
\hline C22:0 Behenic acid & 0.0545 & 0.041 & 0.0237 & 0.039 & $p<0.05$ \\
\hline C23:0 tricosanoic acid & 0.2924 & 0.547 & 0.0359 & 0.044 & $p<0.05$ \\
\hline C22:4n6 (docosatetraenoate) & 0.3470 & 0.211 & 0.1338 & 0.094 & $p<0.05$ \\
\hline C22:5w3 (docosapentaenate) & 0.5866 & 0.128 & 0.7574 & 0.194 & $p<0.05$ \\
\hline C24:0 Lignoceric acid & 0.4644 & 0.769 & 0.0000 & 0.000 & $p<0.05$ \\
\hline $\mathrm{C} 22: 6 n 3 \mathrm{DHA}$ & 2.0641 & 0.538 & 2.5156 & 0.460 & $p<0.05$ \\
\hline C24:1 Nervonic acid & 0.0582 & 0.068 & 0.0000 & 0.000 & $p<0.05$ \\
\hline n3 & 3.9500 & 1.108 & 4.8556 & 1.033 & $p<0.05$ \\
\hline n6 & 24.8704 & 4.869 & 30.0689 & 5.368 & $p<0.05$ \\
\hline SFA & 42.1493 & 6.306 & 42.3087 & 3.965 & NS \\
\hline MUFA & 27.0751 & 5.744 & 22.4911 & 2.249 & $p<0.05$ \\
\hline PUFA & 29.0583 & 5.268 & 34.9245 & 2.365 & $p<0.05$ \\
\hline C18:3n6/C22:4n6 & 0.9162 & 0.686 & 1.8153 & 2.563 & $p<0.05$ \\
\hline
\end{tabular}

haemoglobin (HGB) and for men with the level of ferritin (FER) (Tables 6 and 7, respectively). There were also frequent correlations between $\mathrm{Ca}^{2+}$ and $\mathrm{iPTH}$ in the group of men with CKD, and between $\mathrm{Ca}^{2+}, \mathrm{K}^{+}$, and anthropometric measurements, such as height, weight, BMI, and body surface, in the group of women with CKD. It was also observed that $\mathrm{Na}^{+}$and age did not correlate with any of the analysed FA. In the group of women, C22:4n6n was positively correlated with the duration of the treatment, C-reactive protein (CRP), creatinine (CREA), and decreased saturation of transferrin (\%TSAT).

In group of women with CKD, the most frequent correlations with biochemical and anthropometric parameters 
Table 5 Comparison of the percentages of FFA in the plasma of men with CKD vs. women with CKD

\begin{tabular}{|c|c|c|c|c|c|}
\hline \multirow[t]{2}{*}{ PARAMETER } & \multicolumn{2}{|c|}{ WOMEN (CKD) } & \multicolumn{2}{|c|}{ MEN (CKD) } & \multirow[t]{2}{*}{ p.value } \\
\hline & MEAN & SD & MEAN & SD & \\
\hline C 8:0 Caprylic acid & 0.0071 & 0.022 & 0.0073 & 0.033 & NS \\
\hline C10:0 Capric acid & 0.8944 & 0.638 & 0.9849 & 0.624 & NS \\
\hline C11:0 Undecanoic acid & 0.0209 & 0.13 & 0.0236 & 0.015 & NS \\
\hline C12:0 Lauric acid & 0.1570 & 0.118 & 0.1460 & 0.117 & NS \\
\hline C14:0 Myristic acid & 1.3306 & 0.605 & 1.3045 & 0.793 & NS \\
\hline C14:1 Myristolenic acid & 0.0877 & 0.063 & 0.0788 & 0.073 & NS \\
\hline C15:0 Pentadecanoid acid & 0.3476 & 0.133 & 0.3474 & 0.142 & NS \\
\hline C16:0 Palmitic acid & 27.8720 & 2.781 & 28.6156 & 1.976 & NS \\
\hline C16:1 Palmitoleic acid & 1.9987 & 0.678 & 1.8664 & 0.812 & NS \\
\hline C17:0 Heptadecanoid acid & 0.3519 & 0.088 & 0.3413 & 0.082 & NS \\
\hline C17:1 cis-10- Heptadecanoid acid & 0.1141 & 0.102 & 0.1155 & 0.088 & NS \\
\hline C18:0 Stearic acid & 10.9030 & 1.855 & 11.4695 & 1.451 & $p<0.05$ \\
\hline C18:1n9 ct Oleic acid & 22.8030 & 4.134 & 22.9331 & 3.232 & NS \\
\hline C18:1 tans vaccinic acid & 1.9982 & 0.331 & 2.1048 & 0.304 & $p<0.05$ \\
\hline C18:2n6c Linoleic acid & 17.8470 & 2.910 & 16.8563 & 3.385 & NS \\
\hline C18:3n6 gamma linoleic acid & 0.2418 & 0.123 & 0.1980 & 0.090 & $p<0.05$ \\
\hline C18:3n3 linolenic acid & 0.6727 & 0.307 & 0.6846 & 0.307 & NS \\
\hline C20:0 Arachidic acid & 0.1449 & 0.051 & 0.1623 & 0.051 & $p<0.05$ \\
\hline C22:1/C20:1 cis11- eicosanic acid & 0.2247 & 0.116 & 0.2369 & 0.079 & NS \\
\hline C20:2 cis-11-eicodienoic acid & 0.1893 & 0.059 & 0.2041 & 0.063 & NS \\
\hline C20:3n6 eicosatrienoic acid & 1.1222 & 0.294 & 1.0763 & 0.260 & NS \\
\hline C20:4n6 Arachidonic acid & 5.9699 & 1.299 & 5.7957 & 1.278 & NS \\
\hline C20:5n3 EPA & 0.7960 & 0.371 & 0.7535 & 0.466 & NS \\
\hline C22:0 Behenic acid & 0.0545 & 0.041 & 0.0531 & 0.046 & NS \\
\hline C22:1n9 13 (Erucic acid & 0.2412 & 1.025 & 0.2797 & 1.577 & NS \\
\hline C23:0 tricosanoic acid & 0.2924 & 0.547 & 0.2310 & 0.400 & NS \\
\hline C22:4n6 (docosatetraenoate) & 0.3395 & 0.223 & 0.3203 & 0.205 & NS \\
\hline C22:5w3 (docosapentaenate) & 0.5866 & 0.128 & 0.5764 & 0.172 & NS \\
\hline C24:0 Lignoceric acid & 0.4644 & 0.769 & 0.3034 & 0.852 & NS \\
\hline C22:6n3 DHA & 2.0641 & 0.538 & 1.9231 & 0.660 & NS \\
\hline C24:1 Nervonic acid & 0.0582 & 0.068 & 0.0573 & 0.075 & NS \\
\hline n3 & 3.9500 & 1.108 & 3.8038 & 1.234 & NS \\
\hline n6 & 24.8700 & 4.869 & 23.4958 & 4.914 & NS \\
\hline SFA & 42.1493 & 6.306 & 42.9788 & 7.513 & NS \\
\hline MUFA & 27.0751 & 5.744 & 27.0343 & 5.555 & NS \\
\hline PUFA & 29.0583 & 5.268 & 27.6924 & 5.556 & NS \\
\hline C18:3n6/C22:4n6 & 2.8162 & 2.760 & 2.9674 & 2.551 & NS \\
\hline
\end{tabular}

involved the fatty acids C18:1n9, C18:2n6, C18:3n6, and C22:4n6, which are presented in Table 6. In the group of men with CKD, the most common correlations with the analysed parameters related to $\mathrm{C} 10: 0, \mathrm{C} 16: 0$, and $\mathrm{C} 18: 1 \mathrm{t}$ (Table 7).

\section{Division of groups based on the duration of treatment}

As there were no differences in the tendencies of FA concentration changes between the sexes, and observed relations were dependent on the duration of the treatment, all the patients were divided into six groups based 


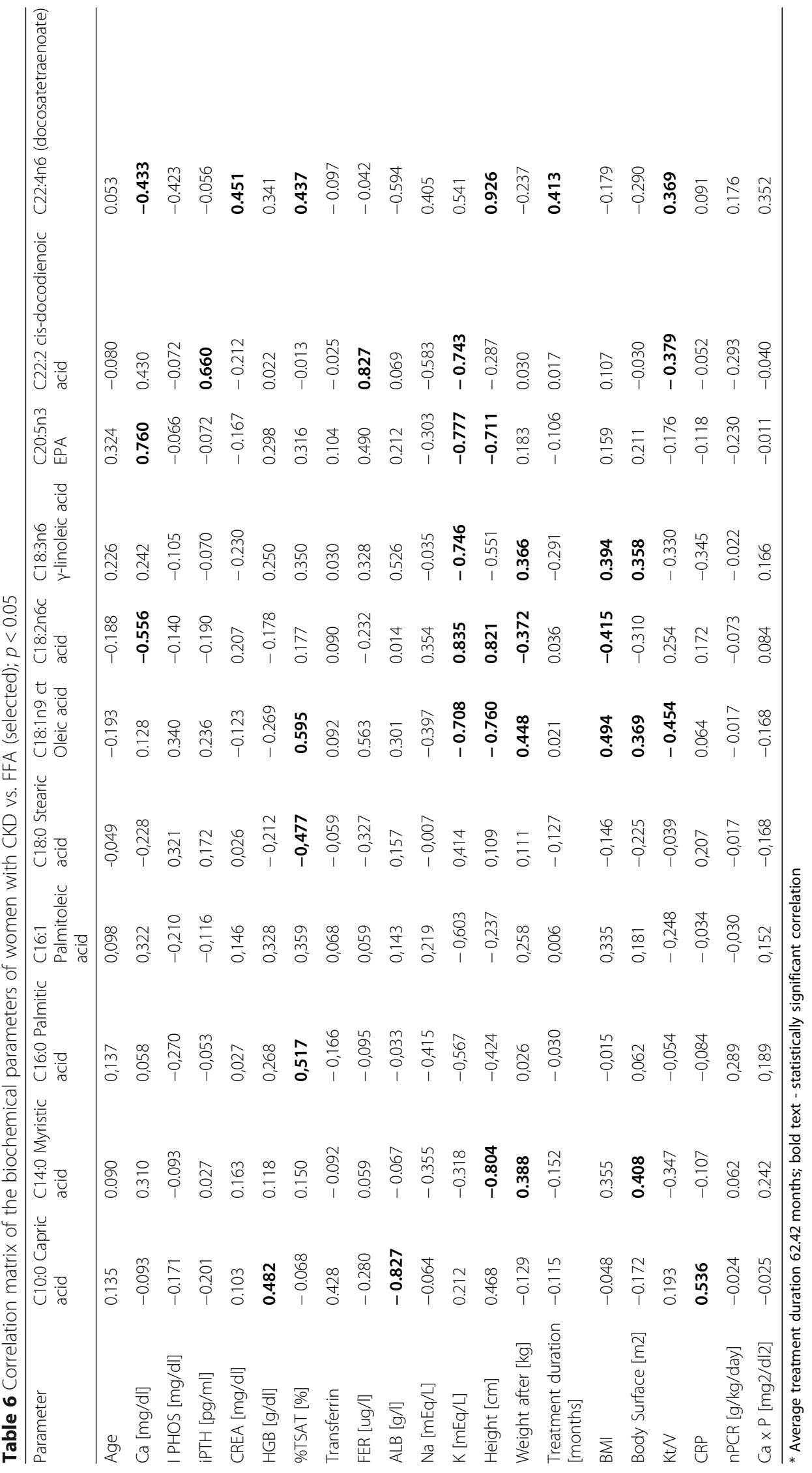


Table 7 Correlation matrix of the biochemical parameters of men with CKD vs. FFA (selected); $p<0.05$

\begin{tabular}{|c|c|c|c|c|c|c|c|c|c|}
\hline Parameter & $\begin{array}{l}\text { C10:0 } \\
\text { Capric } \\
\text { acid }\end{array}$ & $\begin{array}{l}\text { C16:0 } \\
\text { Palmitic } \\
\text { acid }\end{array}$ & $\begin{array}{l}\text { C16:1 } \\
\text { Palmitoleic } \\
\text { acid }\end{array}$ & $\begin{array}{l}\text { C18:0 } \\
\text { Stearic } \\
\text { acid }\end{array}$ & $\begin{array}{l}\text { C18:1n9 ct } \\
\text { Oleic acid }\end{array}$ & $\begin{array}{l}\text { C18:1 tans } \\
\text { vaccinic acid }\end{array}$ & $\begin{array}{l}\text { C18:3n3 } \\
\text { linolenic acid }\end{array}$ & $\begin{array}{l}\text { C20:1 cis11- } \\
\text { eico -sanic acid }\end{array}$ & $\begin{array}{l}\text { C22:4n6 } \\
\text { (docosatetraenoate) }\end{array}$ \\
\hline Age & 0.060 & 0.276 & $-0,185$ & $-0,122$ & -0.304 & 0.028 & -0.187 & -0.170 & 0.173 \\
\hline $\mathrm{Ca}[\mathrm{mg} / \mathrm{dl}]$ & -0.103 & 0.505 & $-0,111$ & 0,389 & -0.412 & -0.423 & -0.222 & -0.057 & -0.311 \\
\hline I PHOS [mg/dl] & -0.304 & -0.635 & $-0,201$ & $-0,352$ & 0.194 & 0.218 & 0.438 & 0.256 & 0.131 \\
\hline iPTH [pg/ml] & -0.159 & -0.595 & 0,017 & $-0,092$ & 0.424 & 0.483 & 0.473 & 0.251 & 0.485 \\
\hline CREA [mg/dl] & 0.190 & 0.109 & $-0,106$ & 0,195 & 0.013 & 0.063 & -0.069 & -0.298 & 0.725 \\
\hline $\mathrm{HGB}[\mathrm{g} / \mathrm{dl}]$ & 0.261 & 0.020 & $-0,075$ & $-0,214$ & 0.197 & -0.019 & -0.102 & -0.124 & 0.232 \\
\hline \%TSAT [\%] & 0.075 & 0.302 & $-0,074$ & 0,185 & -0.333 & 0.035 & 0.011 & -0.059 & 0.364 \\
\hline Transferrin & -0.013 & 0.201 & $-0,044$ & 0,159 & -0.273 & -0.458 & -0.375 & -0.151 & -0.131 \\
\hline FER [ug/l] & 0.433 & -0.034 & 0,021 & $-0,241$ & 0.186 & 0.252 & -0.144 & -0.002 & 0.218 \\
\hline ALB [g/l] & -0.447 & 0.064 & 0,035 & 0,245 & -0.141 & -0.165 & 0.166 & -0.191 & 0.107 \\
\hline $\mathrm{Na}[\mathrm{mEq} / \mathrm{L}]$ & 0.057 & -0.132 & $-0,049$ & 0,047 & -0.190 & 0.201 & 0.131 & -0.128 & 0.364 \\
\hline $\mathrm{K}[\mathrm{mEq} / \mathrm{L}]$ & -0.154 & -0.002 & $-0,140$ & 0,103 & 0.254 & -0.048 & -0.027 & 0.115 & 0.235 \\
\hline Height [cm] & -0.356 & -0.038 & 0,007 & $-0,165$ & 0.137 & 0.222 & 0.121 & 0.125 & -0.067 \\
\hline Weight after [kg] & -0.041 & -0.090 & $-0,110$ & $-0,134$ & 0.102 & 0.032 & -0.055 & 0.194 & -0.117 \\
\hline $\begin{array}{l}\text { Treatment } \\
\text { duration [months] }\end{array}$ & -0.044 & -0.150 & 0,141 & $-0,117$ & 0.174 & 0.353 & -0.015 & 0.099 & 0.436 \\
\hline BMl & 0.186 & -0.071 & $-0,141$ & $-0,015$ & 0.012 & -0.102 & -0.109 & 0.110 & -0.030 \\
\hline Body surface [m2] & -0.260 & -0.256 & $-0,192$ & $-0,254$ & 0.273 & 0.139 & 0.274 & 0.329 & -0.215 \\
\hline $\mathrm{Kt} / \mathrm{N}$ & -0.223 & -0.050 & 0,385 & $-0,061$ & 0.001 & 0.283 & -0.033 & -0.154 & 0.238 \\
\hline CRP & 0.287 & -0.177 & $-0,071$ & $-0,308$ & 0.191 & 0.105 & -0.221 & -0.044 & -0.041 \\
\hline nPCR [g/kg/day] & -0.314 & -0.198 & $-0,152$ & 0,070 & -0.102 & 0.032 & 0.123 & 0.328 & 0.005 \\
\hline Ca $\times$ P [mg2/dl2] & -0.026 & -0.322 & $-0,330$ & 0,094 & -0.112 & -0.181 & 0.088 & 0.098 & -0.154 \\
\hline
\end{tabular}

* Average treatment duration 46,29 months; bold text - statistically significant correlation

on the duration of the treatment. These groups were treated for less than 1 year, up to 2 years, up to 3 years, up to 5 years, up to 10 years, and more than 10 years. Fundamental decreases in the levels of C18:3n6 and C22: 4 n6 were observed after a period longer than 10 years (Table 8). The calculated index $\mathrm{C} 18: 3 \mathrm{n} 6 / \mathrm{C} 22: 4 \mathrm{n} 6$ in particular groups differed significantly in comparison to the group with the longest period of treatment (Table 8). Moreover, the index $\mathrm{C} 18: 3 \mathrm{n} 6 / \mathrm{C} 22: 4 \mathrm{n} 6$ during the period of the first 5 years remained at a stable level, but later on it began to drastically decrease (Fig. 1). Additionally, by analysing the changes dependent on the duration of the treatment, the trend lines of the decrease in the index (C18:3n6/C22:4n6) were determined (Fig. 2).

Table 8 Effect of treatment duration on changes in the C18:3n6/C22:4n6 index

\begin{tabular}{llllll}
\hline Treatment durtion & Average treatment duration [months] & C18:3n6 & C22:4n6 & C18:3n6/C22:4n6 index & Index significance $>10$ years \\
\hline $\begin{array}{l}1 \text { year } \\
N=30\end{array}$ & 6.100 & 0.209 & 3.431 & $1.140 \pm 1.001$ & 0.027717 \\
$\begin{array}{l}2 \text { years } \\
N=26\end{array}$ & 17.654 & 0.211 & 3.851 & $1.169 \pm 1.064$ & 0.025942 \\
$\begin{array}{l}3 \text { years } \\
N=24\end{array}$ & 30.120 & 0.247 & 3.431 & $0.944 \pm 0.539$ & 0.015754 \\
$\begin{array}{l}5 \text { years } \\
N=24\end{array}$ & 48.917 & 0.221 & 3.206 & $1.027 \pm 0.804$ & 0.022576 \\
$\begin{array}{l}10 \text { years } \\
N=24\end{array}$ & 91.667 & 0.216 & 3.866 & $0.675 \pm 0.553$ & NS \\
$>10$ years & 199.71 & & & & - \\
$N=18$ & & 0.188 & 3.134 & $0.491 \pm 0.305$ & \\
\hline
\end{tabular}




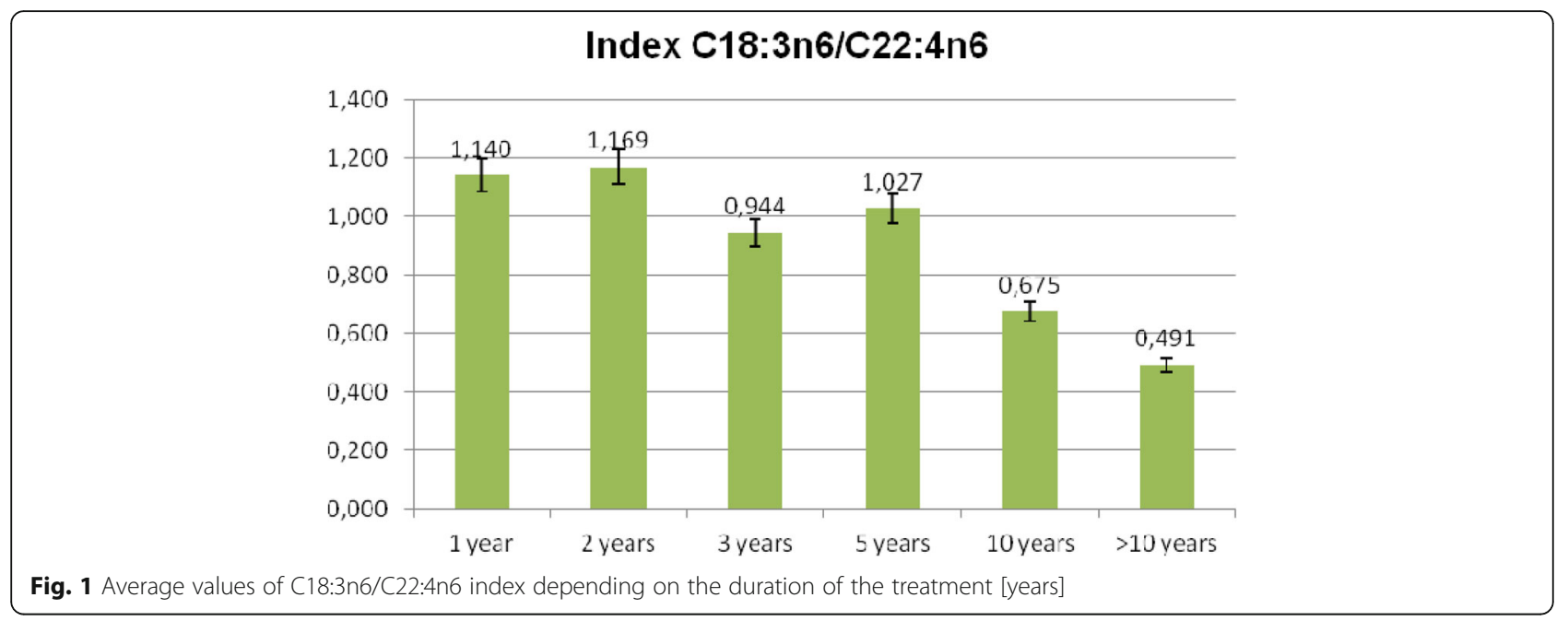

\section{Discussion}

The key enzyme in fatty acid synthesis-responsible for introducing the first cis double bond in the $\Delta 9$ position of the lipotoxic saturated fatty acids stearic acid (C18:0) and palmitic acid (C16:0) - is stearoyl-CoA desaturase 1 (SCD-1). Such reactions generate less lipotoxic monounsaturated fatty acids (MUFA)-oleic acid (C18: 1n-9) and palmitoyl acid (C16: 1n-7), respectively [18]. In this study, the intensification of these reactions was observed in both groups of men and women with CKD. MUFA, which are the products of SCD catalysed reactions, are used as substrates for the synthesis of phospholipids, triglycerides, and cholesterol esters, and thus may increase the lipid burden on tissues and can initiate insulin resistance in patients $[19,20]$. It seems that the intensification of other mechanisms related to SCD-1 activity may occur in the group of women and men with CKD. In our opinion, in the group of women with CKD, the main reason seems to be anthropometric parameters related to fat content, while in the group of men relationships related to calcium and parathyroid hormone levels play a more important role. The adipose tissue synthesises or regulates the production of complement components, in particular C3, in proportion to the amount of adipose tissue that is present. In our studies, we did not examine body fat content, but it is known that women have more than men [21].

Moreover, MUFA also act as mediators of signal transduction, cellular differentiation, and metabolic homeostasis $[18,22]$. Therefore, the changes in FA concentration at this stage may increase the diabetic nephropathy (DN) risk through elevated fat content in the liver [7]. Even though oleic acid is the main component of MUFA consumed in the diet, the regulation of SCD-1 gene expression remains governed by hormonal, environmental, and diet factors. For example, a meal high in carbohydrates can quickly

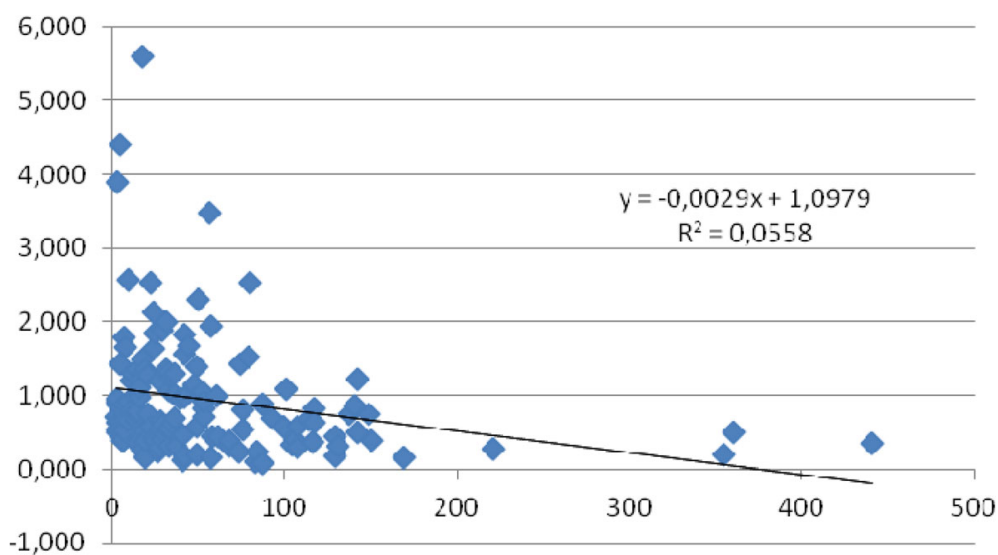

Fig. 2 Trend line showing changes in proportions of C18:3n6/C22:4n6 index vs duration of the treatment [months] 
induce the SCD-1 gene due to an insulin-dependent increase in the activity of the sterol regulatory elementbinding protein (SREBP) -1c and activation of the SCD-1 gene promoter [22]. Other studies show that there exists a SCD regulation on the transcription level, connected to changes in the activity of particular enzymes [23]. These reactions are intensified by oxidative stress, which, due to overproduction of ROS and cellular membrane degradation via lipid peroxidation, may lead to increased levels of myristic acid (C14:0), stearic acid (C18:0), and arachidonic acid (C20:0) [24]. In our study, we observe a slight increase in C14:0 in both sexes, while the other two acids are used in the elongation process. Oxidative processes play a crucial role in damaging renal tubular and renal epithelial cells exposed to ox-LDL activity. Moreover, disrupted transport and FA oxidation, which is accompanied by reduced antioxidative response, damage the structure of podocytes [25]. Podocytes line the outer surface of the basement membrane of the glomerus. Each of the podocytes is linked to more than one arteriole, and each arteriole is covered by several podocytes. Dysregulated lipid metabolism with disrupted metabolism of fatty acids in plasma (FA) is characteristic of metabolic syndrome, obesity, and type 2 diabetes and probably contributes to end-stage renal disease, irrespective of the underlying disease [26].

It was also determined that increased capture of FA by podocytes occurs via increased expression of C36 receptor together with reduced beta-oxidation and, in turn, intracellular lipid accumulation. Therefore, various pathogenetic mechanisms are discussed [25].

Nutritional behaviours have a huge effect on the progression of pathophysiological states. Consumption of food rich in saturated fat accelerates the progression of diseases by the mechanism linked to increased oxidative stress. A study on rats proved that using higher amounts of SFA favours the progression of renal failure [27].

In the cases of all of our patients with CKD (women and men), we observed a decrease in the levels of omega- 6 fatty acids and omega- 3 fatty acids. Lowering the level of both PUFA families means that this substrate is used in the accompanying inflammatory reaction in patients with CKD. In general, PUFA $n-6$ promotes inflammation, whereas PUFA n-3 has anti-inflammatory properties [28]. Due to the fact that PUFA n-6 and n-3 compete for the same enzymes for synthesis and metabolism, their presence in tissues is defined by the profile of lipid mediators involved in inflammatory response [29]. A shift in the PUFA $n-6 / n-3$ ratio is currently regarded to contribute to the prevalence of chronic diseases [30]. In fact, many studies have shown the advantageous effect of PUFA n-3 supplementation in various chronic diseases, which was attributed to antioxidative properties of these fatty acids [31]. Interestingly, elevated levels of fatty acids (FA) before a transplantation may be linked to longer survival of kidney transplants. The pretransplantation level of arachidonic acid (C20:4n6) was independently related to higher survival rates of kidney transplants in multivariate analysis. In one-way analysis, high levels of arachidonic and $\gamma$-linolenic FA (C20:0 i C18:3n6) were linked to a higher percentage of patient survival after transplantation [32]. The percentage of GLA C18:3n6 in groups with CKD (men and women) does not change significantly in comparison to the control group because the intake via the diet is similar. However, the levels of C20:3n6 and C20:4n6 (AA) increase due to higher activity of D6D and D5D. Moreover, EPA and DHA also decrease in both groups with CKD as compared to the control group. There was probably the activation of the resolving pathway of antiinflammatory mediators, synthetizing $\mathrm{E}$ and $\mathrm{D}$ resolvins, protectins, and maresins. Women are more careful about their diet than men and select pro-healthy products, including those rich in omega-3 fatty acids, which could contribute to a greater extent to the activation of the resolution of inflammation. There is an urgent requirement for other, more natural methods supporting the treatment of the disease.

Correlations between anthropometric and biochemical parameters in men and women with CKD showed various relations resulting from the duration of the treatment of both groups of patients (46.29 and 62.46 months, respectively). The observed relations involve capric acid (C10:0) and are connected to the fact that this acid inhibits receptor activator for nuclear factor $\mathrm{K}$ $\mathrm{B}$ ligand (RANKL NF- $\mathrm{kB}$ )-dependent osteoclastogenesis, as the level of capric acid decreases together with a longer period of treatment [33]. Albuminuria is a strong, independent prognostic factor for chronic kidney disease, and ferritin in blood plasma, formed due to cell damage, is a well-known marker of inflammation; thus, the correlations are observable [34, 35]. Elongation of the carbon chain in the $\mathrm{n}-6$ family to C22:4n6 was in the male group linked to fewer parameters characterizing organ function (iPTH, CREA, length of treatment) than in the female group (CREA, \%TSAT, height, length of treatment, and $\mathrm{Kt} / \mathrm{V})$. Elongation of the $\mathrm{n}-6$ family suggests the formation of compounds with mainly proinflammatory activity (prostaglandins, leukotrienes) but also of those responsible for resolving inflammation, such as lipoxins [28]. To determine the activation of certain synthesis pathways will require further studies. The ability to form metabolites from the $n-3$ and $n-6$ series depends on the activity of 6-desaturase (D6D), characteristic of the endoplasmic reticulum [36]. This enzyme depends on non-heme iron proteins, and its activity can be measured by determining the concentration ratio GLA/LA. Moreover, the activity of the enzyme depends on the species, age, sex, and the type of diet [37]. As 
reported by Stawarska et al., a diet low in calories and protein, which is used in CKD, inhibits the activity of this enzyme [38]. Recently, it has been observed that high excretion of both sodium and potassium is linked to increased risk of kidney disease progression in patients with CKD. Multivariate spline regression models suggested a linear correlation between sodium and potassium excretion in urine and the progression of CKD [39]. Therefore, the negative correlations of excreted $\mathrm{K}^{+}$ observed in this study confirm the higher risk of CKD progression in patients with lower concentrations of fatty acids.

We should also draw attention to nervonic acid (C24: 1 ), which is a monounsaturated fatty acid belonging to the omega-9 group. It is formed during the elongation of oleic acid (C18:1) to eicosenoic acid (C20:1) and further elongation to nervonic acid [40]. Erucic acid (22:1) consumed with food can also be elongated to nervonic acid in humans [41]. The data coming from patients with chronic kidney disease show that an increasing level of nervonic acid C24:1 is a significant prognostic marker for patient mortality in the 5th stage of the disease [42]. According to Dołęgowska et al., haemodialysis increases the level of nervonic acid in patients with chronic kidney disease [43]. However, in our own studies, the increase in C24:1, though significant in comparison to the control groups, was not as high as for other chronic diseases [43].

Studies on the relation between plasma monounsaturated fatty acids and the prevalence of heart failure have proved that higher levels of the free fatty acids erucic (C22:1) and nervonic (C24:1) acid are connected with heart failure and may indicate the potential cardiotoxicity of long-chain MUFA in humans [44].

There were numerous mechanisms suggested for the contradictory effects of PUFA $n-6 / n-3$, including (a) competition with PUFA n-6 for metabolism and a reduction in the synthesis of eicosanoids originating from PUFA n-6; (b) down-regulation of key enzymes (e.g., COX-2) which synthesise lipid mediators; (c) direct activity on transcription factors (e.g., NF- $\mathrm{kB}$ ) to inhibit the expression of inflammatory cytokines; and (d) the formation of strong inflammation-resolving compounds (e.g., resolvins, protectins) [45].

When analysing the percentage of particular FA in blood plasma from the patients with CKD, we noticed an increasing amount of C22:4n 6 depending on the duration of the disease. Cells metabolize arachidonic acid (AA) to adrenic acid (AdA-C22:4n6) via elongation of the carbon chain. These fatty acids do not compete with each other for esterification to phospholipids. AdA, but not AA, has a tendency to be incorporated into phospholipids containing stearic acid in the sn-1 position [46]. There are significant differences in the cellular uses of AA and AdA by macrophages, since AdA is released only to phosphatidylcholine, whereas AA is released to various molecules of phosphatidylcholine and phosphatidylinositol [47]. The increase in AdA synthesis is probably linked to the synthesis of new dihomo-IsoF compounds, which are metabolites of adrenic acid [47]. It was determined that in coronary arteries, adrenic acid causes endothelium-dependant relaxations mediated by cyclooxygenase and cytochrome P-450 metabolites. The metabolite of AdA: DH-16, 17-EET, activates $\mathrm{K}(+)$ in smooth muscles, causing hyperpolarization and relaxation of the endothelium in coronary circulation [48]. Moreover, the metabolites of adrenic acid may function as endogenous derivatives of the endothelium and derivatives hyperpolarizing the zona glomerulosa in the adrenal cortex and thus contribute to the regulation of blood circulation in the adrenal gland [49]. This effect, though so far only showed in animals, may be applicable to people.

\section{Conclusions}

To summarize, the course of inflammation in CKD occurs through decreased medium- and increased longchain SFA (the synthesis of MUFA); thus, it is similar to that of other chronic diseases. The dominating cascade of changes is the elongation of GLA-C18:3n6 into DGLA-C20:3n6 and AA-C20:4n6. In the course of CKD progression, along with worsened anthropometric parameters and increased excretion of potassium, the activity of 6-desaturase probably decreases, which reduces the synthesis of EPA and DHA and disables the production of pro-resolving derivatives. With longer duration of the disease, the synthesis of AdA-C22:4n6 increases, and the $\mathrm{C} 18: 3 \mathrm{n} 6 / \mathrm{C} 22: 4 \mathrm{n} 6$ ratio drastically drops after 5 years of disease duration. This parameter can be used to diagnose disease progression. The sample size should be further expanded in future studies, and the influence of cardiovascular and cerebrovascular disease, amyloidosis, multiple myeloma, and other risk factors should be excluded so as to reduce the potential impact on the target value.

\footnotetext{
Abbreviations

AdA-C22:4n6: adrenic acid; ALB: albumin; CKD: chronic kidney disease; CREA: creatinine; CRP: C-reactive protein; CVD: cardiovascular diseases; C18:3n6/C22:4n6: gamma linoleic acid/ docosatetraenoate; DN: diabetic nephropathy; DHA: docosahexaenoic acid; EPA: eicosapentanoic acid; FA: fatty acid; FER: ferritin; GFR: glomerular filtration rate; GLA: gammalinolenic acid; HGB: haemoglobin; iPTH: parathyroid hormone; Kt/N: dialysis adequacy; LA: Linoleic acid; MUFA: monounsaturated fatty acids; NAFLD: non-alcoholic fatty liver disease; PUFA: poly-unsaturated fatty acids; SFA : saturated fatty acids; T2DM: type 2 diabetes
} 


\section{Authors' contributions}

MS- analyzed and interpreted the patient data, prepared figures and the manuscript. MK- collecting material from patients, interpreted the patient data. SM- collecting material from patients, interpreted the patient data. PRcollecting material from patients. AŚD- collecting material from patients. ESanalyzed and interpreted the patient data. All authors read and approved the final manuscript

\section{Funding}

Article is supported by statutory activity Medical University of Gdańsk and Pomeranian Medical University in Szczecin, Poland.

\section{Availability of data and materials}

Please contact author for data requests.

\section{Ethics approval and consent to participate}

All procedures performed in studies involving human participants were in accordance with the ethical standards of the institutional research committee and with the 1964 Helsinki declaration and its later amendments. The Ethics Committee NKEBN/417/2015-ST-48 approved the study protocol.

\section{Consent for publication}

All authors agree to publish this article in the journal of Lipids in Health and Disease.

\section{Competing interest}

The authors declare that they are no conflict of interest in this manuscript.

\section{Author details}

'Department of Human Nutrition and Metabolomics, Pomeranian Medical University in Szczecin, Szczecin, Poland. 'Department of Clinical Nutrition and Dietetics, Medical University of Gdańsk, Gdańsk, Poland. ${ }^{3}$ Department of General Nursery, Medical University of Gdańsk and Diaverum Hemodialysis Unit, Gdańsk, Poland. ${ }^{4}$ Department of Nephrology, Transplantology and Internal Medicine, Medical University of Gdańsk, Gdańsk, Poland.

\section{Received: 19 June 2019 Accepted: 8 April 2020}

\section{Published online: 17 April 2020}

\section{References}

1. Coresh J, Selvin E, Stevens LA, et al. Prevalence of chronic kidney disease in the United States. JAMA. 2007:298:2038-47.

2. Jha V, Garcia-Garcia G, Iseki K, et al. Chronic kidney disease: global dimension and perspectives. Lancet. 2013;382:260-72.

3. Stawarska A, Białek A, Stanimirova I, et al. The effect of conjugated linoleic acids (CLA) supplementation on the activity of enzymes participating in the formation of arachidonic acid in liver microsomes of rats - probable mechanism of CLA anticancer activity. Nutr Cancer. 2015:67:145-55.

4. Hirasawa $A$, Tsumaya $K$, et al. Free fatty acids regulate gut incretin glucagon-like peptide-1 secretion through GPR120. Nat Med. 2005;11(1):904 Epub 2004 Dec 26

5. Afshinnia F, Rajendiran TM, Soni T, et al. Michigan Kidney Translational Core CPROBE Investigator Group. Impaired $\beta$-oxidation and altered complex lipid fatty acid partitioning with advancing CKD. J Am Soc Nephrol. 2018;29(1): 295-306. https://doi.org/10.1681/ASN.2017030350 Epub 2017 Oct 11.

6. Yang P, Xiao Y, Luo X, et al. Inflammatory stress promotes the development of obesity-related chronic kidney disease via CD36 in mice. J Lipid Res. 2017;58(7):1417-1427. doi: 10.1194 / jlr. M076216. Epub 201723 maja.

7. Jia G, Di F, Wang Q, et al. Non-Alcoholic Fatty Liver Disease Is a Risk Factor for the Development of Diabetic Nephropathy in Patients with Type 2 Diabetes Mellitus. PLoS One. 2015; 13:10(11):e0142808. https://doi.org/10. 1371/journal.pone.0142808. eCollection 2015.

8. Zhan YT, Zhang C, Li L, et al. Non-alcoholic fatty liver disease is not related to the incidence of diabetic nephropathy in type 2 diabetes. Int J Mol Sci. 2012;13:14698-706. https://doi.org/10.3390/ijms131114698.

9. Targher G, Bertolini L, Rodella S, et al. Non-alcoholic fatty liver disease is independently associated with an increased prevalence of chronic kidney disease and proliferative/laser-treated retinopathy in type 2 diabetic patients. Diabetologia. 2008;51:444-50.

10. Targher G, Bertolini L, Chonchol M, et al. Non-alcoholic fatty liver disease is independently associated with an increased prevalence of chronic kidney disease and retinopathy in type 1 diabetic patients. Diabetologia. 2010;53: 1341-8. https://doi.org/10.1007/s00125-010-1720-1.

11. Szczuko M, Kaczkan M, Drozd A. et al. Comparison of fatty acid profiles in a Group of Female Patients with chronic kidney diseases (CKD) and metabolic syndrome (MetS)-similar trends of changes, Different Pathophysiology. Int J Mol Sci 2019, 20(7), 1719; https://doi.org/10.3390/ijms20071719.

12. Dobrzyn A, Ntambi JM. The role of Stearoyl-CoA desaturase in body weight regulation. Trends in Cardiovascular Medicine 2004; 14(2): 77-81. https://doi. org/10.1016/j.tcm.2003.12.005.

13. Miyazaki M, Gomez FE, Ntambi JM. Lack of stearoyl-CoA desaturase-1 function induces a palmitoyl-CoA Delta6 desaturase and represses the stearoyl-CoA desaturase-3 gene in the preputial glands of the mouse. J Lipid Res. 2002:43:2146-54.

14. Talarico V, Aloe M, Monzani A, Miniero R, Bona G. Hemolytic uremic syndrome in children. Minerva Pediatr. 2016:68(6):441-55.

15. Pyaram K, Yadav VN, Reza MJ, Sah A Virus-complement interactions: an assiduous struggle for dominance. Futere Virology. 2010: 5(6); 709-730. doi. org/10.2217/fvl.10.60.

16. Holle J, Berenberg-Goßler L, Wu K, et al. Outcome of membranoproliferative glomerulonephritis and C3-glomerulopathy in children and adolescents. Pediatr Nephrol. 2018;33(12):2289-98. https:/doi.org/10.1007/s00467-018-4034-z.

17. Zhang XJ, Huang LL, Su H, Chen, et al. Characterizing plasma phospholipid fatty acid profiles of polycystic ovary syndrome patients with and without insulin resistance using GC-MS and chemometrics approach. J Pharm Biomed Anal. 2014;95:85-92. https://doi.org/10.1016/j.jpba.2014.02.014.

18. Paton CM, Ntambi JM. Loss of stearoyl-CoA desaturase activity leads to free cholesterol synthesis through increased Xbp-1 splicing. Am J Physiol Endocrinol Metab. 2010:299(6):E1066-75.

19. Rachek LI. Free fatty acids and skeletal muscle insulin resistance. Prog Mol Biol Transl Sci. 2014;121:267-92. https://doi.org/10.1016/B978-0-12-800101-1.00008-9.

20. Pereira S, Park E, Mori $Y$, et al. FFA-induced hepatic insulin resistance in vivo is mediated by PKC $\delta$, NADPH oxidase, and oxidative stress. Am J Physio Endocrinol Metab. 2014;1:307(1):E34-46. doi: https://doi.org/10.1152/ ajpendo.00436.2013. Epub 2014 May 13.

21. Barbu A, Hamad OA, Lind L, Ekdahl KN, Nilsson B. The role of complement factor C3 in lipid metabolizm. Mol Immunol. 2015; 67(1): 101-107. doi.org/ 10.1016/j.molimm.2015.02.027.

22. Paton $\mathrm{CM}, \mathrm{Ntambi}$. Biochemical and physiological function of stearoyl-CoA desaturase. Am J Physiol Endocrinol Metab 2008;297: E28-E37.

23. Singh $\mathrm{K}$, Hartley DG, McFadden $\mathrm{TB}$, et al. Dietary fat regulates mam mary stearoyl coA desaturase expression and activity in lactating mice. J Dairy Res. 2004;71(1):1-6.

24. Ross IA, Boyle $T$, Johnson WD, et al. Free fatty acids profile of the fetal brain and the plasma, liver, brain and kidneys of pregnant rats treated with sodium arsenite at mid-organogenesis. Toxicol Ind Health. 2010; 26 (10): 657-666. doi: 10.1177 / 0748233710375952. Epub 2010, 14 lipca.

25. Nosadini R, Tonolo G. Role of oxidized low density lipoproteins and free fatty acids in the pathogenesis of glomerulopathy and tubulointerstitial lesions in type 2 diabetes. Nutr Metab Cardiovasc Dis. 2011:21(2):79-85. https://doi.org/10.1016/j.numecd.2010.10.002.

26. Sieber J, Jehle AW. Free Fatty acids and their metabolism affect function and survival of podocytes. Front Endocrinol (Lausanne). 2014;5:186. doi: 10. 3389 / fendo.2014.00186. eCollection 2014.

27. Ibraheem ZO, Sattar MA, Abdullah NA, et al. Effect of high saturated free fatty acids feeding on progression of renal failure in rat model of experimental nephrotoxicity. Bosn J Basic Med Sci. 2012;12(1):26-32.

28. Serhan CN, Chiang N, Van Dyke TE. Resolving inflammation: dual antiinflammatory and pro-resolution lipid mediators. Nat Rev Immunol. 2008;8: 349-61. https://doi.org/10.1038/nri2294.

29. Kaliannan $\mathrm{K}$, Wang $\mathrm{B}$, Li X-Y, et al. A host-microbiome interaction mediates the opposing effects of omega- 6 and omega- 3 fatty acids on metabolic endotoxemia. Sci Rep. 2015:5:11276.

30. Kang JX. The omega-6/omega-3 fatty acid ratio in chronic diseases: animal models and molecular aspects. World Rev Nutr Diet. 2011;102:22-9. https:// doi.org/10.1159/000327787

31. Wall R, Ross RP, Fitzgerald GF, et al. Fatty acids from fish: the antiinflammatory potential of long-chain omega-3 fatty acids. Nutr Rev. 2010;68: 280-9. https://doi.org/10.1111/j.1753-4887.2010.00287x.

32. Baker AC, De Mattos, Watkins $S$, et al. Pretransplant free fatty acids (FFA) and allograft survival in renal transplantation. J Surg Res. 2010;164(2):182-7. https://doi.org/10.1016/j.jss.2010.07.038. 
33. Kim HJ, Yoon HJ, Kim SY, et al. A medium-chain fatty acid, capric acid, inhibits RANKL-induced osteoclast differentiation via the suppression of NF$\mathrm{KB}$ signaling and blocks cytoskeletal organization and survival in mature osteoclasts. Mol Cells. 2014;37(8):598-604. doi: https://doi.org/10.14348/ molcells.2014.0153.

34. Carson JM, Okamura K, Wakashin $\mathrm{H}$, et al. Podocytes degrade endocytosed albumin primarily in lysosomes. PLoS One. 2014;9(6):e99771. https://doi.org/ 10.1371/journal.pone.0099771 eCollection 2014.

35. Kell DB, Pretorius E. Serum ferritin is an important inflammatory disease marker, as it is mainly a leakage product from damaged cells. Metallomics. 2014;6(4):748-73. https://doi.org/10.1039/c3mt00347g.

36. Guillou H, Zadravec D, Martin PG, et al. The key roles of elongases and desaturases in mammalian fatty acids metabolism: insights from transgenic mice. Prog Lipid Res. 2010;49:186-99.

37. Wadhwani NS, Manglekar RR, Dangat KD, et al. Effect of maternal micronutrients (folic acid, vitamin B12) and omega 3 fatty acids on liver fatty acid desaturases and transport proteins in Wistar rats. Prostaglandins Leukot Essent Fat Acids. 2012;86:21-7.

38. Stawarska A, Tokarz A, Seweryn T. Wpływ wybranych czynników dietetycznych na aktywność $\Delta 6$-desaturazy w mikrosomach wątrobowych szczurów. Bromatol Chem Toksykol. 2012;3:427-32.

39. He J, Mills KT, Appel LJ, et al. and for the Chronic Renal Insufficiency Cohort Study Investigators. Urinary Sodium and Potassium Excretion and CKD Progression. J Am Soc Nephrol. 2016; 27(4): 1202-1212. Published online 2015 Sep 17. doi: https://doi.org/10.1681/ASN.2015010022.

40. Pickens CA, Sordillo LM, Comstock SS, et al. Plasma phospholipids, nonesterified plasma polyunsaturated fatty acids and oxylipids are associated with BMI. Prostaglandins Leukot Essent Fat Acids. 2015;95:31-40.

41. Imamura F, Lemaitre RN, King IB, et al. Long-chain monounsaturated fatty acids and incidence of congestive heart failure in two prospective cohorts. Circulation. 2013;127(14):1512-22.

42. Shearer GC, Carrero JJ, Heimbürger O, et al. Plasma fatty acids in chronic kidney disease: Nervonic acid predicts mortality. J Ren Nutr. 2012;22(2):277-83.

43. Dołęgowska B, Kwiatkowska E, Wesołowska T, et al. Effect of hemodialysis on the content of fatty acids in monolayers of erythrocyte membranes in patients with chronic renal failure. Renal Failure 2007;29: 447-452.

44. Gaggini M, Morelli M, et al. Non-alcoholic fatty liver disease (NAFLD) and its connection with insulin resistance, dyslipidemia, atherosclerosis and coronary heart disease. Nutrients. 2013;10:5(5):1544-60. doi: https://doi.org/ 10.3390/nu5051544.

45. Kang JX, Weylandt KH. Modulation of inflammatory cytokines by omega-3 fatty acids. Subcell Biochem. 2008;49:133-43. https://doi.org/10.1007/978-1 4020-8831-5_5.

46. Guijas C, Astudillo AM, Gil-de-Gómez L, et al. Phospholipid sources for adrenic acid mobilization in RAW 264.7 macrophages. Comparison with arachidonic acid. Biochim Biophys Acta. 2012;1821(11):1386-93. https://doi. org/10.1016/j.bbalip.2012.07.010.

47. de La Torre A, Lee YY, Oger C, Sangild PT, et al. Synthesis, discovery, and quantitation of dihomo-isofurans: biomarkers for in vivo adrenic acidperoxidation. Angew Chem Int Ed Eng. 2014;10:53(24): 6249-6252. doi: 10.1002/anie. 201402440.

48. Yi XY, Gauthier KM, Cui L, et al. Metabolism of adrenic acid to vasodilatory 1 alpha, 1 beta-dihomo-epoxyeicosatrienoic acids by bovine coronary arteries. Am J Physiol Heart Circ Physiol. 2007;292(5):H2265-74.

49. Kopf PG, Zhang DX, Gauthier KM, et al. Adrenic acid metabolites as endogenous endothelium-derived and zona glomerulosa-derived hyperpolarizing factors. Hypertension. 2010;55(2):547-54. https://doi.org/10 1161/Hypertensionaha.109.144147.

\section{Publisher's Note}

Springer Nature remains neutral with regard to jurisdictional claims in published maps and institutional affiliations.

Ready to submit your research? Choose BMC and benefit from:

- fast, convenient online submission

- thorough peer review by experienced researchers in your field

- rapid publication on acceptance

- support for research data, including large and complex data types

- gold Open Access which fosters wider collaboration and increased citations

- maximum visibility for your research: over $100 \mathrm{M}$ website views per year

At $\mathrm{BMC}$, research is always in progress.

Learn more biomedcentral.com/submissions 